\title{
Occurrence of Helicobacter pylori and Epstein-Barr virus infection in endoscopic and gastric cancer patients from Northern Brazil
}

Carolina Rosal Teixeira de Souza ${ }^{1 * \dagger}$, Kátia Soares de Oliveira ${ }^{2 \dagger}$, Jefferson José Sodré Ferraz ${ }^{3}$, Mariana Ferreira Leal ${ }^{4,5}$, Danielle Queiroz Calcagno ${ }^{6}$, Aline Damasceno Seabra', André Salim Khayat ${ }^{6}$, Raquel Carvalho Montenegro ${ }^{1}$, Ana Paula Negreiros Nunes Alves ${ }^{7}$, Paulo Pimentel Assumpção ${ }^{6}$, Marília Cardoso Smith ${ }^{5}$

and Rommel Rodríguez Burbano ${ }^{1}$

\begin{abstract}
Background: Helicobacter pylori (HP) and Epstein-Barr virus (EBV) have been associated with cancer development. We evaluated the prevalence of HP, HP CagA ${ }^{+}$and EBV infection in gastric cancer (GC) samples from adults and in gastric tissues from patients who underwent upper endoscopy (UE).

Methods: Samples from UE and GC were collected to investigate the presence of HP infection and the HP virulence factor CagA by a urease test and PCR. The presence of EBV was detected by Eber-1 in situ hybridization.

Results: In UE, $85.5 \%$ of juvenile patients showed some degree of gastritis (45.3\% of patients with mild gastritis and $54.7 \%$ with moderate/severe gastritis) and patients with mild gastritis were younger than patients with moderate/ severe gastritis. Among adults, 48.7\% presented mild gastritis and 51.3\% moderate/severe gastritis. HP infection was detected in $0 \%$ of normal mucosa, $58.5 \%$ of juvenile gastritis patients, $69.2 \%$ of adult gastritis patients and $88 \%$ of GC patients. In these same groups, HP CagA ${ }^{+}$was detected in $0 \%, 37.7 \%, 61.5 \%$ and $67.2 \%$ of tissue samples, respectively. In juvenile patients, HP infection was more common in those with gastritis than in normal samples $(p=0.004)$. The patients with either HP or HP CagA $A^{+}$were older than patients without these pathogens $(p<0.05)$. In juvenile patients, HP infection was more frequent in cases of moderate/severe gastritis than in cases of mild gastritis $(p=0.026)$. Moreover, in patients with GC, HP infection was more frequent in males than in females $(p=0.023)$. GC patients with $\mathrm{HP} \mathrm{CagA} A^{+}$were older than patients with HP CagA $(p=0.027)$. HP Cag $A^{+}$was more common in intestinal-type than diffuse-type GC $(p=0.012)$. HP Cag $A^{+}$was also associated with lymph-node $(p=0.024)$ and distal $(p=0.005)$ metastasis. No association between EBV infection and HP infection or any clinicopathological variable was detected.
\end{abstract}

Conclusions: Our results suggest that HP is involved in the pathophysiology of severe gastric lesions and in the development of GC, particularly when $\mathrm{CagA}^{+}$is present. EBV was not the primary pathogenic factor in our samples.

Keywords: Helicobacter pylori, Epstein-Barr virus, Gastritis, Gastric cancer

\footnotetext{
* Correspondence: carolrosalts@gmail.com

${ }^{\dagger}$ Equal contributors

'Laboratório de Citogenética Humana, Instituto de Ciências Biológicas,

Universidade Federal do Pará, Rua Augusto Corrêa, 01 - Guamá. CEP

66075-110. Caixa postal 479, Belém, PA, Brasil

Full list of author information is available at the end of the article
} 


\section{Background}

Gastric cancer (GC) and other gastrointestinal diseases occur at high rates worldwide [1], and infections involving viruses and bacteria have been associated with these diseases. Recently, several studies have been performed to understand the role of pathogens that infect the human stomach, particularly Helicobacter pylori (HP) and Epstein-Barr virus (EBV), in gastric carcinogenesis [2-5].

HP, a Gram-negative spiral bacterium, is considered a public health problem. In 1994, the International Agency for Research on Cancer (IARC) defined HP as a group 1 carcinogen [6,7]. This bacterium colonizes the gastric mucosa of more than $50 \%$ of the world's population [8]. However, only approximately $20 \%$ of infected individuals develop severe gastric diseases such as GC. Among the factors- that have been suggested to contribute to development of gastric disease in HP-infected patients are the virulence of HP strains, the permissiveness of the gastric environment and the host genetic background [9]. The HP cytotoxicity associated gene A ( CagA) is one of the most significant virulence factors of this bacteria, and it has been associated with risk for GC [10].

EBV infects more than $90 \%$ of the global adult population, and most individuals are infected during childhood. Upon infection, the virus remains latent in B lymphocytes throughout life [5]. To be oncogenic, EBV must maintain its genome inside host cells to avoid cell death and to evade recognition by the immune system. The contribution of EBV to gastric carcinogenesis has not been fully elucidated $[11,12]$. EBV infects epithelial cells from the oropharynx and subsequently spreads to the lymphoid tissues where it infects B lymphocytes [13-15]. Atrophic gastritis may induce the infiltration of EBVcarrying lymphocytes and increase the chance of their contact with the gastric epithelial cells. On the other hand, the gastric inflammation may also produce a cytokine-rich microenvironment to support clonal growth of EBVinfected epithelial cells [16].

In developing countries such as Brazil, HP and EBV infections are particularly prevalent within lower socioeconomic populations. Furthermore, infection occurs at earlier ages in these populations compared to developed countries [17-19]. Studies are needed to determine these pathogens' association with and influence on the development of gastric diseases at earlier ages, where they could initiate or promote carcinogenic processes. Additionally, the role of HP and EBV in the development of gastric adenocarcinoma in the elderly, the population where this disease is most prevalent, remains unclear.

Therefore, this study aimed to assess the prevalence of HP and EBV infection, as well as the CagA-positive status of HP, in gastric tissues from juvenile and adult patients undergoing upper endoscopy (UE) and in tumor specimens from adult patients with GC.

\section{Methods}

\section{Samples}

The present study included: (i) gastric tissue samples from 62 juvenile patients ranging from 12 months to 18 years old, referred for UE to clarify clinical manifestations within the upper gastrointestinal tract, (ii) gastric tissue samples from 39 adult patients ranging from 19 to 61 years old, referred for UE to clarify clinical manifestations within the upper gastrointestinal tract, and (iii) tumor samples from 125 adults, 26 to 89 years old, with primary gastric adenocarcinoma. Samples were randomly collected during the period of 2005-2013 in Belém city of Pará State, Northern Brazil. Informed consent was obtained prior to sample collection from all adult patients or from the parents or guardians of all juvenile patients. Sample collection was carried out with the approval of the ethics committee of the Human Institute of Health Sciences of the Federal University of Pará (Protocol \#35/ 2010) and João de Barros Barreto University Hospital (Protocol \#142004). All patients had negative histories of exposure to chemotherapy and radiotherapy prior to sample collection, and no patient presented with cooccurrence of diagnosed cancers. Data on the clinical features of patients were collected from medical records.

\section{Histopathology}

Endoscopic findings were classified according to the updated Sydney System [20] which considers the degree of inflammation, activity, atrophy and intestinal metaplasia. For each patient, 5 biopsies of gastric tissues were evaluated: 2 from the antral region of the stomach, 1 from the incisura angularis, and 2 from the oxyntic mucosa. Chronic gastritis was designated as mild, moderate or severe.

Gastric tumors were classified according to the Lauren classification [21] and staged using standard criteria by pTNM staging [22]. Tables 1 and 2 show the clinicopathological features of gastritis and GC samples, respectively.

\section{$\mathrm{HP}$ and CagA detection}

The presence of HP was detected by a commercially available rapid urease test (Promedical, Brazil), and the negative results were confirmed by PCR using the oligonucleotides described by Covacci et al. [23]. All gastric samples were placed in a tube containing $2 \%$ Christensen's urea agar and examined for urea hydrolysis after $24 \mathrm{~h}$ of incubation at $37^{\circ} \mathrm{C}$. In the presence of urease produced by $\mathrm{HP}$, the urea is converted to ammonia, resulting in a change of $\mathrm{pH}$ and, consequently, the color of the solution.

The detection of the CagA gene was carried out by PCR in the gastric mucosa of all patients, using the oligonucleotides described by Covacci et al. [23]. All reactions were performed in duplicate. A sample was considered positive 
Table 1 Clinicopathological features, H. pylori and EBV infection in gastritis samples of juvenile patients

\begin{tabular}{|c|c|c|c|c|c|c|c|c|c|}
\hline \multirow[t]{2}{*}{ Variable } & \multicolumn{3}{|c|}{ H. pylori } & \multicolumn{3}{|c|}{$\operatorname{Cag} A$} & \multicolumn{3}{|c|}{ EBV } \\
\hline & Negative & Positive & $p$-value & Negative $^{c}$ & Positive & $p$-value & Negative & Positive & $p$-value \\
\hline Age (years, Mean \pm SD) & $7.45 \pm 3.88$ & $12.19 \pm 4.09$ & $<0.001^{*}$ & $8.88 \pm 4.49$ & $12.45 \pm 4.01$ & $0.005^{*}$ & $9.96 \pm 4.5$ & $17 \pm 1.41$ & $0.033^{*}$ \\
\hline \multicolumn{10}{|l|}{ Gender $[N(\%)]$} \\
\hline Female & $14(42.4)$ & $19(57.6)$ & $0.685^{\mathrm{a}}$ & $23(69.7)$ & $10(30.3)$ & $0.096^{\mathrm{a}}$ & $32(97.0)$ & $1(3.0)$ & $0.626^{a}$ \\
\hline Male & $8(40.0)$ & $12(60.0)$ & & $10(50.0)$ & $10(50.0)$ & & $19(95.0)$ & $1(5.0)$ & \\
\hline \multicolumn{10}{|c|}{ Histological subtype [N(\%)] } \\
\hline Mild & $16(66.7)$ & $8(33.3)$ & $0.026^{* b}$ & $20(83.3)$ & $4(16.7)$ & $0.108^{b}$ & $23(95.8)$ & $1(4.2)$ & $0.136^{\mathrm{b}}$ \\
\hline Moderate/Severe & $6(20.7)$ & $23(79.3)$ & & $13(44.8)$ & $16(55.2)$ & & $28(96.6)$ & $1(3.4)$ & \\
\hline \multicolumn{10}{|l|}{ EBV infection [N(\%)] } \\
\hline Absent & $21(41.2)$ & $30(58.8)$ & $0.242^{b}$ & $31(60.8)$ & $20(39.2)$ & $0.998^{b}$ & & & \\
\hline Present & $1(50)$ & $1(50)$ & & $2(100)$ & $0(0)$ & & & & \\
\hline
\end{tabular}

*Significant difference between groups, $\mathrm{p}<0.05 .{ }^{\mathrm{a}} \mathrm{p}$ value after adjustment for age; ${ }^{\mathrm{b}} \mathrm{p}$ value after adjustment for age and gender; ${ }^{\mathrm{c}} \mathrm{Negative}$ samples for $\mathrm{H}$. $\mathrm{pylori}$ and samples with H. pylori infection but without CagA virulence factor; EBV: Epstein-Barr virus; SD: standard deviation.

if a visible and clear band was observed on a $2 \%$ agarose electrophoresis gel.

\section{EBV detection}

EBV was detected by RNA in situ hybridization (ISH) with a 30-bp biotinylated probe (5'-AGACACCGTC CTCACCACCCGGGACTTGTA-3') complementary to EBV-encoded small RNA-1 (Eber1), the most abundant viral product in latently infected cells [24]. Signal amplification was achieved with a mouse anti-biotin antibody (clone BK, 1:20 dilution; DakoCytomation ${ }^{\circ}, \mathrm{CA}, \mathrm{USA}$ ) and biotinylated rabbit anti-immunoglobulin antibody (polyclonal, 1:100 dilution; DakoCytomation ${ }^{\circ}, \mathrm{CA}, \mathrm{USA}$ ). The reaction was detected with streptavidin-biotin peroxidase complex (DakoCytomation ${ }^{\circ}, \mathrm{CA}, \mathrm{USA}$ ) and diaminobenzidine chromogen (DakoCytomation ${ }^{\circ}$, CA, USA). The slides were counterstained with Harris's hematoxylin. Cell analysis was performed by 2 independent investigators using light microscopy, at 40x or 20x magnification. A total of 10 representative microscopic fields were evaluated, and fields containing less than 5 cells were not considered. A gastric cancer sample positive for EBV was included as a positive control, and two slides treated without probe were used as negative controls. Samples where 5\% or more of the epithelial cells contained brown/red staining were considered positive. Although lymphocytes were also found to be infected by EBV, we did not include infected lymphoid cells in our analysis.

\section{Statistical analyses}

The Shapiro-Wilk test was used to evaluate the distribution of age data and to determine the appropriate subsequent test for statistical comparison. The MannWhitney test (non-parametric) or T-test for independent samples (parametric) was used to compare ages between the groups. Associations between HP or EBV

Table 2 Clinicopathological features, $H$. pylori and EBV infection in gastritis samples of adults patients

\begin{tabular}{|c|c|c|c|c|c|c|c|c|c|}
\hline \multirow[t]{2}{*}{ Variable } & \multicolumn{3}{|c|}{ H. pylori } & \multicolumn{3}{|c|}{$\operatorname{CagA}$} & \multicolumn{3}{|c|}{ EBV } \\
\hline & Negative & Positive & $p$-value & Negative $^{c}$ & Positive & $p$-value & Negative & Positive & $p$-value \\
\hline Age (Mean \pm SD) & $35.58 \pm 7.82$ & $45.00 \pm 10.89$ & $0.011^{*}$ & $37.6 \pm 7.67$ & $44.92 \pm 11.75$ & $0.039^{*}$ & $42.24 \pm 11.14$ & $39.50 \pm 3.54$ & 0.733 \\
\hline \multicolumn{10}{|l|}{ Gender $[\mathrm{N}(\%)]$} \\
\hline Female & $3(21.4)$ & $11(78.6)$ & $0.410^{a}$ & $5(35.7)$ & $9(64.3)$ & $0.915^{\mathrm{a}}$ & $14(100)$ & $0(0)$ & $0.999^{a}$ \\
\hline Male & $9(36.0)$ & $16(64.0)$ & & $10(40.0)$ & $15(60.0)$ & & $23(92.0)$ & $2(8.0)$ & \\
\hline \multicolumn{10}{|c|}{ Histological subtype [N(\%)] } \\
\hline Mild & $7(36.8)$ & $12(63.2)$ & $0.715^{b}$ & $9(47.4)$ & $10(52.6)$ & $0.820^{b}$ & $17(89.5)$ & $2(10.5)$ & $0.999^{b}$ \\
\hline Moderate/Severe & $5(25.0)$ & $15(75.0)$ & & $6(30.0)$ & $14(70.0)$ & & $20(100)$ & $0(0)$ & \\
\hline \multicolumn{10}{|c|}{ EBV infection [N(\%)] } \\
\hline Absent & $12(32.4)$ & $25(67.6)$ & $0.999^{b}$ & $14(37.8)$ & $23(62.2)$ & $0.810^{b}$ & & & \\
\hline Present & $0(0)$ & $2(100)$ & & $1(50.0)$ & $1(50.0)$ & & & & \\
\hline
\end{tabular}

*Significant difference between groups, $\mathrm{p}<0.05 .{ }^{\mathrm{a}} \mathrm{p}$ value after adjustment for age; ${ }^{\mathrm{b}} \mathrm{p}$ value after adjustment for age and gender; ${ }^{\mathrm{c}} \mathrm{Negative}$ samples for $\mathrm{H}$. $\mathrm{pylori}$ and samples with H. pylori infection but without CagA virulence factor; EBV: Epstein-Barr virus; SD: standard deviation. 
and other clinicopathological features were analyzed using chi-square $\left(\mathrm{X}^{2}\right)$ and logistic regression. A p-value less than 0.05 was considered significant, and the confidence interval was $95 \%$.

\section{Results}

We investigated 226 individuals, including 92 women and 134 men, divided into three groups. The percentage of men was $38.7 \%, 64.1 \%$ and $68 \%$ for juvenile UE patients, adult UE patients and GC patients, respectively. The proportion of males was higher in the cohort of GC patients ( $p<0.001$, $\mathrm{OR}=3.365,95 \% \mathrm{CI}=1.784-6.345)$ and adult UE patients $(\mathrm{p}=0.014, \mathrm{OR}=2.827,95 \% \mathrm{CI}=1.233-6.485)$ than among juvenile UE patients.

Among juvenile UE patients, 40 patients presented gastritis by UE. However, $59 \%$ of patients without UEdiagnosed gastritis presented mild gastritis by histopathological analysis. Therefore, 53 (85.5\%) patients showed some degree of gastritis in the group of juvenile UE patients. The age of patients without gastritis did not differ from that of patients with gastritis [median \pm interquartile range (IQR): $7.33 \pm 8$ vs $10.23 \pm 8$ years old; $\mathrm{p}=0.080$, Mann-Whitney test]. However, patients with mild gastritis were younger than patients with moderate or severe gastritis (mean \pm standard deviation (SD): $8.25 \pm 4.30 .90$ vs $11.86 \pm 4.27$ years old; $\mathrm{p}=0.004$, $\mathrm{T}$-test). The gender breakdown did not differ between juvenile patients with and without gastritis $(\mathrm{p}=0.725)$, as well as between juvenile patients with mild gastritis and moderate or severe gastritis $(\mathrm{p}=0.097)$.

Among adult UE patients, all of the evaluated individuals presented gastritis, including 19 (48.7\%) with mild gastritis and $20(51.3 \%)$ with moderate or severe gastritis. Patients with mild gastritis were younger than patients with moderate or severe gastritis (mean \pm SD: $37.47 \pm 7.20$ vs $46.50 \pm 12.07$ years old; $\mathrm{p}=0.003$, T-test). The gender breakdown did not differ between juveniles patients with mild gastritis and moderate or severe gastritis $(p=1)$ in this group of analysis.

HP infection was detected in $0 \%$ of normal gastric mucosa samples, $58.5 \%$ of samples from juvenile gastritis patients, $69.2 \%$ of adult gastritis samples and $88 \%$ of GC patients (Figure 1a). In juvenile individuals, HP infection was more frequently observed in gastritis samples than in normal samples $(\mathrm{p}=0.004$, Yates correction). The frequency of HP in adult gastritis did not differ from the observed frequency of gastritis in juvenile patients $(\mathrm{p}=1.000$, after adjustment for age and gender) or in the GC samples ( $\mathrm{p}=0.335$, after adjustment for age and gender).

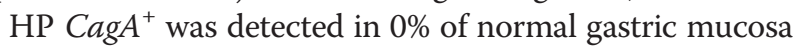
samples, $37.7 \%$ of samples from juvenile gastritis patients, $61.5 \%$ of adult gastritis samples and $67.2 \%$ of GC patients (Figure 1b). The frequency of infection by $\mathrm{HP} \mathrm{CagA}^{+}$did not differ between samples from juvenile patients with gastritis and normal gastric mucosa $(\mathrm{p}=0.064$, Yates correcton). Moreover, the frequency of $\mathrm{HP} \mathrm{CagA}^{+}$in adult gastritis tissue samples did not differ from that observed in juvenile gastritis patients $(p=1$, after adjustment for age and gender) or in GC samples ( $\mathrm{p}=0.500$, after adjustment for age and gender).

The frequency of HP infection did not differ between males and females in the samples from juvenile or adult patients evaluated by UE ( $p>0.05$, after adjustment for age; Tables 1 and 2). However, in GC samples, HP infection was detected more frequently in males than in females $(\mathrm{p}=0.023 \mathrm{OR}=3.651,95 \% \mathrm{CI}=1.190-11.199$, after adjustment for age; Table 3 ).

In juvenile patients who underwent UE, gastritis patients with HP infection and with $\mathrm{HP} \mathrm{CagA}^{+}$were older than those without this pathogen $(\mathrm{p}<0.001$ and $\mathrm{p}=0.005$, respectively, T-test; Table 1 ). In this group of patients, $\mathrm{HP}$ infection was more prevalent in cases of moderate or severe gastritis than in those of mild gastritis $(\mathrm{p}=0.026$; $\mathrm{OR}=5.136,95 \% \mathrm{CI}=1.220-21.611$, after adjustment for

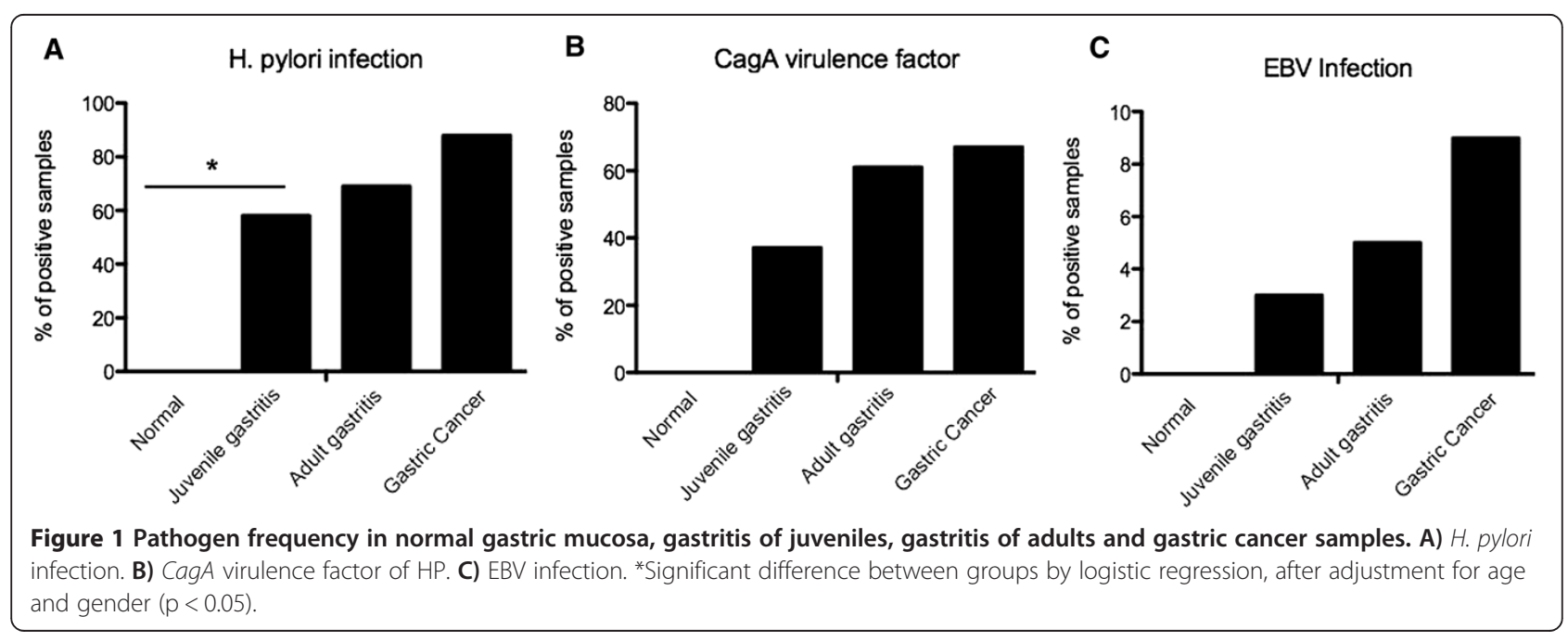


Table 3 Clinicopathological features, H. pylori and EBV infection in gastric tumors

\begin{tabular}{|c|c|c|c|c|c|c|c|c|c|}
\hline \multirow[t]{2}{*}{ Variable } & \multicolumn{3}{|c|}{ H. pylori } & \multicolumn{3}{|c|}{ CagA } & \multicolumn{3}{|c|}{ EBV } \\
\hline & Negative & Positive & $\overline{p \text {-value }}$ & Negative $^{c}$ & Positive & $\overline{p \text {-value }}$ & Negative & Positive & $\overline{p \text {-value }}$ \\
\hline Age (Median \pm IQR) & $57 \pm 25$ & $64 \pm 16.75$ & $0.027^{*}$ & $57 \pm 22$ & $64.5 \pm 16.5$ & $0.027^{*}$ & $63 \pm 20$ & $67 \pm 21.5$ & 0.192 \\
\hline \multicolumn{10}{|l|}{ Gender $[N(\%)]$} \\
\hline Female & $9(22.5)$ & $31(77.5)$ & $0.023^{* a}$ & $15(37.5)$ & $25(62.5)$ & $0.307^{\mathrm{a}}$ & $39(97.5)$ & $1(2.5)$ & $0.115^{\mathrm{a}}$ \\
\hline Male & $6(7.1)$ & $79(92.9)$ & & $26(30.6)$ & $59(69.4)$ & & $74(87.1)$ & $11(12.9)$ & \\
\hline \multicolumn{10}{|c|}{ Tumor location [N(\%)] } \\
\hline Non-cardia & $12(16.4)$ & $61(83.6)$ & $0.080^{\mathrm{b}}$ & $26(35.6)$ & $47(64.4)$ & $0.519^{b}$ & $67(91.8)$ & $6(8.2)$ & $0.592^{b}$ \\
\hline Cardia & $3(5.8)$ & $49(94.2)$ & & $15(28.8)$ & $37(71.2)$ & & $46(88.5)$ & $6(11.5)$ & \\
\hline \multicolumn{10}{|c|}{ Histological subtype [N(\%)] } \\
\hline Intestinal-type & $6(8.5)$ & $65(91.5)$ & $0.247^{b}$ & $25(46.3)$ & $29(53.7)$ & $0.012^{* b}$ & 63(88.7) & $8(11.3)$ & $0.650^{\mathrm{b}}$ \\
\hline Diffuse-type & $9(16.7)$ & $45(83.3)$ & & $16(22.5)$ & $55(77.5)$ & & $50(92.6$ & $4(7.4)$ & \\
\hline \multicolumn{10}{|l|}{ Stage $[N(\%)]$} \\
\hline Early & $7(15.9)$ & $37(84.1)$ & $0.680^{\mathrm{b}}$ & $25(56.8)$ & $19(43.2)$ & $0.000^{* b}$ & 41 (93.2) & $3(6.8)$ & $0.999^{\mathrm{b}}$ \\
\hline Advanced & $6(8.3)$ & $66(91.7)$ & & $14(19.4)$ & $58(80.6)$ & & $64(88.9)$ & $8(11.1)$ & \\
\hline \multicolumn{10}{|c|}{ Tumor invasion [N(\%)] } \\
\hline $\mathrm{T} 1 / \mathrm{T} 2$ & $4(13.3)$ & $26(86.7)$ & $0.453^{b}$ & $13(43.3)$ & $17(56.7)$ & $0.616^{\mathrm{b}}$ & $29(96.7)$ & $1(3.3)$ & $0.560^{\mathrm{b}}$ \\
\hline $\mathrm{T} 3 / \mathrm{T} 4$ & $11(11.6)$ & $84(88.4)$ & & $28(29.5)$ & $67(70.5)$ & & $84(88.4)$ & $11(11.6)$ & \\
\hline \multicolumn{10}{|c|}{ Lymph node metastasis $[\mathrm{N}(\%)]$} \\
\hline Absent & $3(25)$ & $9(75.0)$ & $0.193^{b}$ & $8(66.7)$ & $4(33.3)$ & $0.024^{* b}$ & $12(100)$ & $0(0)$ & $0.999^{b}$ \\
\hline Present & $12(10.6)$ & $101(89.4)$ & & $33(29.2)$ & $80(70.8)$ & & $101(89.4)$ & $12(10.6)$ & \\
\hline \multicolumn{10}{|c|}{ Distant metastasis $[\mathrm{N}(\%)]$} \\
\hline Absent & $11(16.7)$ & $55(83.3)$ & $0.136^{\mathrm{b}}$ & $30(45.5)$ & $36(54.5)$ & $0.005^{* b}$ & $62(93.9)$ & $4(6.1)$ & $0.258^{\mathrm{b}}$ \\
\hline Present & $4(6.8)$ & $55(93.2)$ & & $11(18.6)$ & $48(81.4)$ & & $51(86.4)$ & $8(13.6)$ & \\
\hline \multicolumn{10}{|l|}{ EBV infection $[\mathrm{N}(\%)]$} \\
\hline Absent & $15(13.3)$ & $98(86.7)$ & $0.998^{b}$ & $39(34.5)$ & $74(65.5)$ & $0.358^{b}$ & & & \\
\hline Present & $0(0)$ & $12(100)$ & & $2(16.7)$ & $10(83.3)$ & & & & \\
\hline
\end{tabular}

*Significant difference between groups, $p<0.05$. ${ }^{\mathrm{a}} \mathrm{p}$ value after adjustment for age; ${ }^{\mathrm{b}} \mathrm{p}$ value after adjustment for age and gender; ${ }^{\mathrm{c}} \mathrm{Negative}$ samples for $\mathrm{H}$. $p y l o r i$ and samples with H. pylori infection but without CagA virulence factor; EBV: Epstein-Barr virus; IQR: interquartile range.

age and gender; Table 1). As observed in juvenile patients, adults with gastritis who were also positive for HP infection and HP $\mathrm{CagA}^{+}$were older than those without this pathogen $(\mathrm{p}=0.011$ and $\mathrm{p}=0.039$, respectively, $\mathrm{T}$-test; Table 2).

In tumor samples, patients with $\mathrm{HP} \mathrm{CagA}^{+}$were older than patients without HP CagA $(\mathrm{p}=0.027$, Mann-Whitney test; Table 3). HP CagA ${ }^{+}$was more prevalent in intestinaltype than diffuse-type GC ( $\mathrm{p}=0.012 ; \mathrm{OR}=2.741,95 \%$ CI $1.252-6.001$, after adjustment for age and gender; Table 3). The presence of HP $\operatorname{CagA}+$ was also associated with lymph node metastasis $(\mathrm{p}=0.024$; $\mathrm{OR}=5.611$, $95 \% \mathrm{CI}=1.255-25.097$, after adjustment for age and gender) and distal metastasis ( $\mathrm{p}=0.005$; OR 3.299, 95\% $\mathrm{CI}=1.441-7.556$, after adjustment for age and gender; Table 3).

EBV infection was detected in $0 \%$ of normal gastric mucosa samples, $3.8 \%$ of samples from juvenile gastritis patients, 5.1\% of samples from adult gastritis patients and $9.6 \%$ of GC patients (Figure 1c and Figure 2). In the gastric mucosa, we found that $5-15 \%$ of cells were infected. Rates of EBV infection did not differ among normal gastric mucosa and mucosa from juvenile patients with gastritis ( $p>0.05$, Yates correction). Moreover, the frequency of EBV infection in the gastritis of adults did not differ from that observed in the gastritis of juvenile patients and GC samples ( $p>0.05$, after adjustment for age and gender). No association between EBV infection and HP infection or any clinicopathological variable was found ( $p>0.05$, Table 1, 2 and 3 ).

Although we did not observe a statistically significant association between the two pathogens, only one EBVpositive case was found without concomitant HP infection. This case was an 18-year-old female with no sign of gastric disease by UE evaluation and mild gastritis by histopathological analysis. 


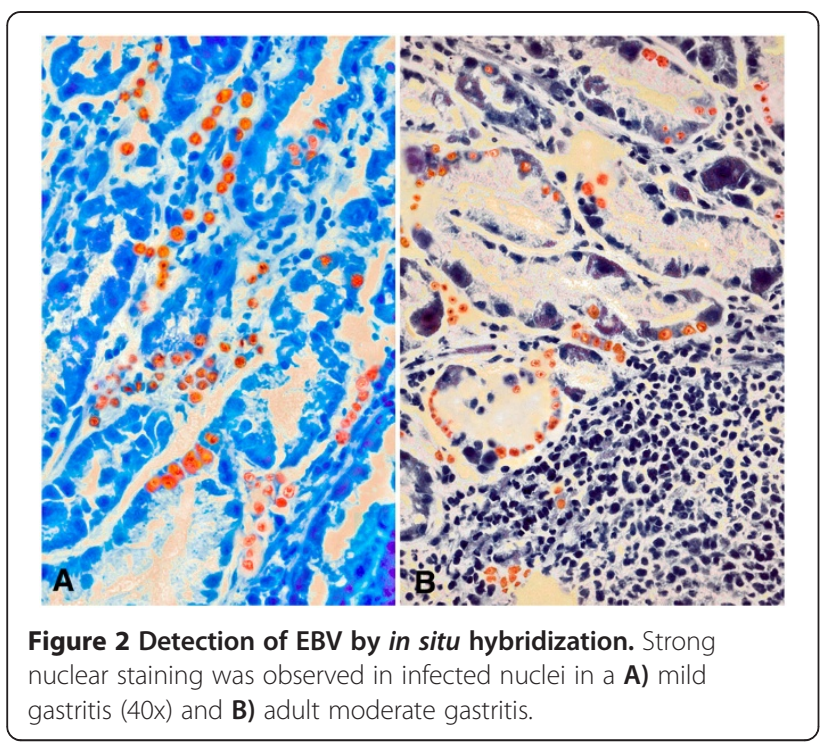

\section{Discussion}

Infection by HP and EBV occurs most often during childhood, and both viruses can synergistically enhance the alteration of gastric mucosa to chronic gastritis and GC $[6,17,19,25]$.

Gastritis is more likely to occur in older adults but can affect people of all ages, including children. Many studies $[26,27]$ have attempted to understand the development of gastritis in children. Souza et al. [28], identified endoscopic abnormalities in $74 \%$ of the children and adolescents studied. Among these, 26\% (7/21) had gastritis as determined by UE. In our study, gastritis was identified by UE in a larger number of juvenile patients (40/62). However, finding an apparently normal mucosa by endoscopy does not exclude the possibility of pathological change, as biopsy is required for a definitive determination. Our results confirm this assertion because in 22 normal endoscopic exams, only 9 showed a normal histological pattern. In addition, patients with mild gastritis were younger than patients with moderate or severe gastritis, perhaps because they had not yet been exposed to many aggressive agents that can lead to gastritis [6].

In the present study, HP infection was detected in most of the UE patients and GC samples, although the techniques used may underestimate the presence of the bacteria. Other studies in Brazil, such as those by Gatti et al. [29] and Souza et al. [28], reported the prevalence of HP infection in juveniles to be $51 \%$ and $60 \%$, respectively. These results are consistent with our findings. An investigation in other developing countries also showed a similar frequency (61.8\%) [30]. In adults, a slightly higher frequency was found in other studies in Brazilian (88.4\%) [31] and African (70-97\%) populations [32]. These numbers most likely reflect the social and health conditions of the studied populations because infections by HP are more common in developing countries than in developed countries [19].

In our study, HP infection was more common in cases of moderate or severe gastritis than in juveniles with mild gastritis. Similarly, Álvarez et al. [31] found a higher frequency of moderate and severe gastritis in patients infected by HP. Additionally, we observed that the prevalence of HP, particularly HP $\mathrm{CagA}{ }^{+}$, increased with age, corroborating previous investigations in populations from northeastern Brazil, China, and Japan [31-33]. It has been suggested that the earlier HP infection occurs, the greater the risk for GC due to chronic inflammatory reactions to the infection [34]. In the population studied here, the frequency of infection by HP or HP $\mathrm{CagA}^{+}$in GC patients did not differ from that observed in adults patients with gastritis. However, some studies have found that the spontaneous disappearance of HP during malignant transformation of gastric epithelia is possible [35,36]. Nevertheless, cancer still occurs after successful eradication of HP; therefore, eradication of HP does not lead to a significant decrease in the incidence of gastric cancer [37]. Furthermore, it has been observed that the eradication of HP must occur before carcinomatous change develops [38]. This finding highlights the necessity of epidemiological studies to understand the incidence and prevalence of HP in a population and to help in the development of population-specific strategies to prevent and control HP.

The prevalence of HP in gastric tumors varies with the country being analyzed [39]. In Brazil, a previous study detected this bacteria in $85.7 \%$ of gastric tumor samples [40], which is similar to the frequency observed in our study (88\%). In addition, we observed that the frequency of HP was 1.5-times greater in GC samples than in juvenile gastritis samples, and almost ninety times higher than in normal gastric mucosa, highlighting a strong association between HP and the process of gastric carcinogenesis. After initial infection by HP, patients develop acute gastritis. This may resolve spontaneously, but the majority of cases progress to chronic gastritis [41]. The clinical outcome of HP infection is determined by the complex interaction between host factors and bacteria [42]. CagA is likely the most significant virulence factor [43] and is strongly associated with the risk for GC [42]. It is known that the basic CagA genotype acquired in childhood remains throughout life [44].

HP CagA $A^{+}$strains have been associated with more intense inflammation and greater bacterial density, as well as progression to gastric atrophy, peptic ulcer and gastric cancer [43]. However, the involvement of HP CagA ${ }^{+}$ in gastric carcinogenesis in Brazilian individuals is still controversial. Oliveira et al. [45] found an association between the presence of CagA with more marked antral 
inflammation in duodenal ulcers (90\%) and gastric carcinoma (94.23\%) in Brazilian adults. In another study of the Brazilian population, Gatti et al. [29] found a slightly greater frequency $(69 \%)$ of $\mathrm{CagA}^{+}$in patients with chronic gastritis. However, the authors did not find any association between $\mathrm{CagA}^{+}$strains and chronic gastritis, suggesting that other bacterial factors are involved in disease genesis. Consistent with this, in our study we did not find an association between $\mathrm{HP} \mathrm{CagA}^{+}$and the presence of gastritis. However, $\mathrm{HP} \mathrm{CagA}^{+}$was associated with poor prognostic variables in $\mathrm{GC}$ cancer.

Here, the $\mathrm{CagA}^{+}$genotype was associated with the age, histological subtype and metastatic process of GC patients. Unlike Kuo et al. [46], we found a higher frequency of $\mathrm{CagA}^{+}$patients in the older cohort of our Brazilian population. Moreover, the presence of $\mathrm{HP} \mathrm{CagA}^{+}$was higher in intestinal-type than in diffuse-type GC. The transformation in gastric mucosa induced by $\mathrm{HP} \mathrm{CagA}{ }^{+}$is similar to the alterations that occur in the intestinal-type of GC $[2,47]$; thus, finding the highest frequency $(84.6 \%)$ of $\mathrm{CagA}^{+}$in intestinal-type GC is reasonable. Additionally,

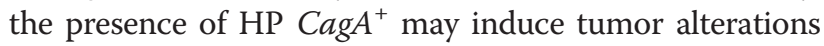
that lead to metastasis. Kong et al. [48] observed that HP stimulates the synthesis of CACUL1 in a gastric tumor cell line, which in turn promotes the expression of matrix metalloproteinase 9 and increases invasion and metastasis.

Approximately 7\% of our patients presented EBV infection in gastric tissue samples. None of these patients presented symptoms of mononucleosis. Therefore, EBV infection in gastric mucosa is not necessarily associated with infection in lymph nodes or tonsils.

The frequency of infection by EBV in GC (9.6\%) was similar to the frequency previously described in other populations (approximately 7.3 - 13\%) [49-51]. However, the prevalence of EBV infection in patients with gastritis (3.8\% among juvenile and 5.1\% among adults) was reduced in comparison to the prevalence reported in the literature. Ryan et al. [25] found EBV sequences in 83\% $(5 / 6)$ of adult and $30 \%(15 / 50)$ of pediatric gastritis lesions. The low frequency identified in gastric mucosa of the younger patients may be because the stomach is not the primary location for B lymphocytes immortalized by EBV infection. The gastric mucosa does not seem to possess the necessary homing mechanism for settlement by these infected lymphocytes [5].

Although our results suggest that EBV is not critical for the initial steps of gastric mucosal injury in the Brazilian population, the presence of EBV genomes and their expression in gastric carcinoma cells raises the possibility that this virus may contribute to neoplastic transformation. Notably, EBV was found within the malignant cells in approximately $10 \%$ of gastric adenocarcinomas, and this infection seems to precede malignant transformation [52]. Additionally, a previous in vitro study reported that reactive products from $\mathrm{HP}$ infection trigger EBV reactivation in latently infected gastric epithelial cells [53]. Inflammatory stress that occurs during the malignization of gastric cells may lead to infiltration of lymphocytes carrying EBV. This process may increase the possibility of contact with epithelial cells, or it may produce a rich medium that supports the cytokine-stimulated clonal replication of EBV-infected epithelial cells [16].

Recently, Cárdenas-Mondragón [54] reported that coinfection with EBV and HP CagA ${ }^{+}$was associated with the presence of severe gastritis, reveling a critical role for EBV in gastric mucosal alterations. Here, we did not find an association between EBV and HP or the presence of CagA in our gastritis or cancer samples, most likely due to the low frequency of EBV.

The main limitation of this study is its relatively small sample size. Therefore, some of the statistical analyses presented reduced the power to detect significant differences between groups. Therefore, further investigations are still necessary to fully understand the roles of EBV and $\mathrm{HP}$ in gastric carcinogenesis in the Brazilian population.

\section{Conclusion}

Our results strongly suggest that HP is involved in the pathophysiology of severe gastric lesions and development of GC in infected juveniles and adults. Furthermore, the frequency of these pathologies increases with age. HP $\mathrm{CagA}^{+}$was associated with greater inflammation and more advanced stage of cancer. EBV was not the primary pathogenic factor in our sample. Additionally, a better understanding of the most prevalent strains of pathogens, and their associated antigens, will be valuable for the development of vaccines clinical protocols for screening and treating infection.

\section{Abbreviations}

HP: Helicobacter pylori; EBV: Epstein-Barr virus; UE: Upper endoscopy; GC: Gastric cancer; IARC: International agency for research on cancer; CagA: Cytotoxin associated gene A.

\section{Competing interest}

The authors declare that they have no competing interests.

\section{Authors' contributions}

CRTS: acquired data, analyzed and interpreted data, performed statistical analysis, wrote and revised the manuscript; KSO: acquired data, analyzed and interpreted data, wrote and revised the manuscript; JJSF: acquired data and revising it critically for important intellectual content; MFL: designed the study and performed the statistical analysis; DQC: designed the study, assisted with revision of the manuscript through contribution of important intellectual content; ADS: performed the statistical analysis and revised the manuscript; ASK: performed the statistical and revised the manuscript ; RCM: analyzed and interpreted data, revised the manuscript; APNNA: pathological analysis; PPA: acquisition of funding and acquired data; MCS: re-analyzed and re-interpreted data, and revised the manuscript; RRB: conceived of the study, participated in its design and coordination and helped to draft the manuscript. All authors read and approved the final manuscript. 


\section{Authors' information}

CRTS: Biomedical research with PhD in Genetic and Molecular Biology, experience in Human Genetics with an emphasis on carcinogenesis and molecular markers, as well as experience in diagnostic imaging; KSO: professor at School of Medicine - UFPA; JJSF: pharmaceutical assistant professor at University Center of Pará (CESUPA) with a PhD in Cell Biology; MFL: researcher at the Department of Orthopedics and Traumatology and at the Department of Morphology and Genetics -UNIFESP, with experience in genetics and gastric cancer; DQC: visiting professor at the Center for Research in Oncology-UFPA, with experience in genetics and gastric cancer; ADS: PhD student in Genetics and Molecular Biology at UFPA; ASK: associate professor at the Institute of Biological Sciences and Center for Research in Oncology-UFPA, with experience in genetics with an emphasis on Human and Medical Genetics; RCM: assistant professor at UFPA, experience in pharmacology with an emphasis on oncology; APNNA: pathologist and professor at UFC; PPA: surgeon at University Hospital João de Barros Barreto-UFPA, experience in oncology and gastroenterology; MCS: Full professor of genetics, Head of Genetics Division, experience in Human Genetics and cancer; RRB: associate professor at the Institute of Biological Sciences-UFPA, experience in Human Genetics with an emphasis on carcinogenesis and mutagenesis.

\section{Acknowledgements}

The authors are thankful to Conselho Nacional de Desenvolvimento Científico e Tecnológico (CNPq; CRTS, ASK, RCM and RRB); Fundação de Amparo à Pesquisa do Estado de São Paulo (FAPESP; MFL and DQC); Coordenação de Aperfeiçoamento de Pessoal de Nível Superior (CAPES; ADS), which supported this study through grants and fellowships.

\section{Author details}

'Laboratório de Citogenética Humana, Instituto de Ciências Biológicas, Universidade Federal do Pará, Rua Augusto Corrêa, 01 - Guamá. CEP 66075-110. Caixa postal 479, Belém, PA, Brasil. Instituto de Ciências da Saúde, Universidade Federal do Pará, Belém, PA, Brasil. ${ }^{3}$ Centro Universitário do Pará, Belém, PA, Brasil. ${ }^{4}$ Departamento de Ortopedia e Traumatologia, Universidade Federal de São Paulo, São Paulo, SP, Brazil. ${ }^{5}$ Disciplina de Genética, Departamento de Morfologia e Genética, Universidade Federal de São Paulo, São Paulo, SP, Brasil. ${ }^{6}$ Núcleo de Pesquisa em Oncologia, Universidade Federal do Pará, Belém, PA, Brasil. 'Departamento de Patologia Oral, Faculdade de Odontologia, Universidade Federal do Ceará, Fortaleza, CE, Brasil.

Received: 23 January 2014 Accepted: 1 October 2014 Published: 15 October 2014

\section{References}

1. Boyle P, Levin B: World CanCer report 2008. Cancer Control 2008, 199(Book, Edited):512.

2. Ding S, Goldberg J, Hatakeyama M: Helicobacter pylori infection, oncogenic pathways and epigenetic mechanisms in gastric carcinogenesis. Future Oncol 2010, 6:851-862.

3. Eslick G-D: Helicobacter pylori infection causes gastric cancer? A review of the epidemiological, meta-analytic, and experimental evidence. World J Gastroenterol 2006, 12:2991-2999.

4. Fukayama M, Ushiku T: Epstein-Barr virus-associated gastric carcinoma. Pathol Res Pract 2011, 207:529-537.

5. Thompson MP: Epstein-Barr Virus and Cancer. Clin Cancer Res 2004, 10:803-821.

6. Nagini S: Carcinoma of the stomach: A review of epidemiology, pathogenesis, molecular genetics and chemoprevention. World J Gastrointest Oncol 2012, 4:156-169.

7. IARC: Schistosomes, liver flukes and Helicobacter pylori. IARC Working Group on the Evaluation of Carcinogenic Risks to Humans. IARC Monogr Eval Carcinog Risks Hum 1994, 61:1-241.

8. Bücker R, Azevedo-Vethacke M, Groll C, Garten D, Josenhans C, Suerbaum S, Schreiber S: Helicobacter pylori colonization critically depends on postprandial gastric conditions. Sci Rep 2012, 2:994.

9. Das JCPN: Epidemiology and pathophisiology of helicobacter pylori infection children. Indian J Pediatr 2007, 74:287-290.

10. Delahay RM, Rugge M: Pathogenesis of Helicobacter pylori infection. Helicobacter 2012, 17(Sup 1):9-15.
11. Imai S, Koizumi S, Sugiura M, Tokunaga M, Uemura Y, Yamamoto N, Tanaka S, Sato E, Osato T: Gastric carcinoma: monoclonal epithelial malignant cells expressing Epstein-Barr virus latent infection protein. Sci USA 1994, 91:9131-9135.

12. Oda K, Tamaru J, Takenouchi T, Mikata A, Nunomura M, Saitoh N: Association of Epstein-Barr virus with gastric carcinoma with lymphoid stroma. Am J Pathol 1993, 143:1063-1071.

13. lezzoni J, Gaffey M, Weiss L: The role of Epstein-Barr virus in lymphoepithelioma-like carcinomas. Am J Clin Pathol 1995, 103:308-315.

14. Wu MS, Shun CT, Wu CC, Hsu TY, Lin MT, Chang MC, Wang HP, Lin JT: Epstein-Barr virus-associated gastric carcinomas: relation to H. pylori infection and genetic alterations. Gastroenterology 2000, 118:1031-1038.

15. Tsuchiya S: Diagnosis of Epstein-Barr virus-associated diseases. Crit Rev Oncol Hematol 2002, 44:227-238.

16. Saiki Y, Otani H, Naito Y, Miyazawa M, Nagura H: Immunophenotypic characterization of Epstein-Barr virus-associated gastric carcinoma: mas- sive infiltration by proliferating CD8+ T-lymphocytes. Lab Invest 1996, 75:67-76.

17. Rodrigues $\mathrm{O}$, Moraes E, Fernandes M, Sassi R, Rodrigues F, Pinheiro H: Prevalência do Helicobacter pylori em adolescentes submetidos à esofagogastroduodenoscopia. Vitalle 2009, 21:51-58.

18. De Oliveira AM, Rocha GA, Queiroz DM, Mendes EN, de Carvalho AS, Ferrari TC, Nogueira AM: Evaluation of enzyme-linked immunosorbent assay for the diagnosis of Helicobacter pylori infection in children from different age groups with and without duodenal ulcer. J Pediatr Gastroenterol Nutr 1999, 28:157-161.

19. Hunt RH, Xiao SD, Megraud F, Leon-Barua R, Bazzoli F, van der Merwe $S$, Coelho LGV, Fock M, Fedail S, Cohen H, Malfertheiner P, Vakil N, Hamid S, Goh KL, Wong BCY, Krabshuis J, Le MA: Helicobacter Pylori in Developing Countries. 2010:1-15.

20. Dixon MF, Genta RM, Yardley JH, Correa P: Classification and grading of gastritis: the Updated Sydney System. Am J Surg Pathol 1996, 20:1161-1181

21. Lauren $\mathrm{P}$ : The two histological main types of gastric carcinoma: diffuse and so-called intestinal-type carcinoma. An attempt at a histo-clinical classification. Acta Pathol Microbiol Scand 1965, 64:31-49.

22. Washington $\mathrm{K}: 7$ th edition of the AJCC cancer staging manual: stomach. Ann Surg Oncol 2010, 17:3077-3079.

23. Covacci A, Rappuolu R: PCR amplification of gene sequences form Helicobacter pylori strains. In Helicobacter pylori techniques for clinical diagnosis and basic research. Edited by Lee and F Mégraud. London: WB Saunders Company Ltda; 1996:94-109.

24. Bacchi CE, Bacchi MM, Rabenhorst SH, Soares FA, Fonseca LE Jr, Barbosa HS, Weiss LMGA: AIDS-related lymphoma in Brazil: histopathology, immunophenotype, and association with Epstein-Barr virus. Am J Clin Pathol 1996, 105:230-237.

25. Ryan JL, Shen Y, Morgan DR, Leigh B, Kenney SC, Dominguez RL, Margaret L: Epstein-Barr Virus Infection is Common in Inflamed Gastrointestinal Mucosa. Dig Dis Sci 2012, 57:1887-1898.

26. Uhlig HH, Tannapfel A, Mössner J, Jedwilayties S, Deutscher J, Müller DM, Kiess WRT: Histopathological parameters of Helicobacter pyloriassociated gastritis in children and adolescents: comparison with findings in adults. Scand J Gastroenterol 2003, 38:701-706.

27. Whitney A, Guarner J, Hutwagner L, Gold B: Helicobacter pylori Gastritis in Children and Adults: Comparative Histopathologic Study. Ann Diagn Pathol 2000, 4:279-285.

28. Souza D, Cipolotti R, Filho M: Achados das endoscopias digestivas altas em crianças e adolescentes de Sergipe. Rev Paul Pediatr 2008, 26:361-364.

29. Gatti LL, Lábio R, Silva LC, Smith Mde APS: CagAPositive Helicobacter pylori in Brazilian Children Related to Chronic Gastritis. Braz J Infect Dis 2006, 10:254-258.

30. Ricuarte O, Gutierrez O, Cardona H, Kim JG, Graham DY, El-Zimaity HMT: Atrophic gastritis in young children and adolescents. J Clin Pathol 2005, 58:1189-1193.

31. Álvares MMD, Marino M, de Oliveira CA, Mendes CC, de Costa ACF, Guerra J, Queiroz, Dulciene Maria de Magalhães Nogueira AMMF: Características da gastrite crônica associada a Helicobacter pylori : aspectos topográficos, doenças associadas e correlação com o status cag A. J Bras Patol e Med Lab 2006, 42:51-59.

32. Holcombe C: Helicobacter pylori: the African Enigma. Gut 1992, 33:429-431. 
33. Xu X, Liu F, Zhang S, Zhao J, Shi J: Analysis on Helicobacter pylori infection and its related diseases in 1,442 children in Tianjin city. Zhonghua Liu Xing Bing Xue Za Zhi 2000, 21:100-102.

34. Recavarren-Arce S, Gilman RH, Leon-Barua R, Salazar G, McDonald J, Lozano R, Diaz F, Ramirez-Ramos A, Berendson R: Chronic atrophic gastritis: early diagnosis in a population where Helicobacter pylori infection is frequent. Clin Infect Dis 1997, 25:1006-1012.

35. Kokkola A, Kosunen TU, Puolakkainen P, Sipponen P, Harkonen M, Laxen F, Virtamo J, Haapiainen R, Rautelin H: Spontaneous disappearance of Helicobacter pylori antibodies in patients with advanced atrophic corpus gastritis. APMIS 2003, 111:619-624.

36. Perri F, Pastore M, Clemente R, Festa V, Quitadamo M, Niro G, Conoscitore P, Rutgeerts $P$, Andriulli A: Helicobacter pylori infection may undergo spontaneous eradication in children: a 2-year follow-up study. J Pediatr Gastroenterol Nutr 1998, 27:181-183.

37. Wong BC-Y, Lam SK, Wong WM, Chen JS, Zheng TT, Feng RE, Lai KC, Hu WHC, Yuen ST, Leung SY, Fong DYT, Ho J, Ching CK, Chen JS: Helicobacter Pylori Eradication to Prevent Gastric Cancer in a High-Risk Region of China: a Randomized Controlled Trial. APMIS 2003, 111(6):619-624.

38. Kato M, Asaka M: Recent knowledge of the relationship between Helicobacter pylori and gastric cancer and recent progress of gastroendoscopic diagnosis and treatment for gastric cancer. Jpn J Clin Oncol 2010, 40:828-837.

39. Helicobacter A: Gastric cancer and Helicobacter pylori: a combined analysis of 12 case control studies nested within prospective cohorts. Gut 2001, 49:347-353.

40. Thomazini CM, Aparecida M, Rodrigues M: Infecção por Helicobacter pylori e câncer gástrico : freqüência de cepas patogênicas cagA e vacA em pacientes com câncer gástrico. J Bras Patol Med Lab 2006, 42:25-30.

41. Tan VP, Wong BC: Helicobacter pylori and gastritis: untangling a complex relationship 27 years on. J Gastroenterol Hepatol 2011, 26(SUp 1):42-45.

42. Ladeira M, Salvadori D, Rodrigues M: Biopatologia do Helicobacter pylori. J Bras Patol Med Lab 2003, 39:335-342.

43. Stein M, Ruggiero P, Rappuoli R, Bagnoli F: Helicobacter pylori CagA: From Pathogenic Mechanisms to Its Use as an Anti-Cancer Vaccine. Front Immunol 2013, 4(October):328.

44. Yamaoka Y, Reddy R, Graham DY: Helicobacter pylori virulence factor genotypes in children in the United States: clues about genotype and outcome relationships. J Clin Microbiol 2010, 48:2550-2551.

45. Oliveira AG, Santos A, Guerra JB, Rocha GA, Rocha AMC, Oliveira CA, Cabral MMDA, Nogueira AMMF, Queiroz DMM: babA2- and cagA-positive Helicobacter pylori strains are associated with duodenal ulcer and gastric carcinoma in Brazil. J Clin Microbiol 2003, 41:3964-3966.

46. Kuo SH, Chen LT, Lin CW, Wu MS, Hsu PN, Tsai HJ, Chu CY, Tzeng YS, Wang $\mathrm{HP}$, Yeh $\mathrm{KH}$, Cheng $\mathrm{A}$ : Detection of the Helicobacter pylori CagA protein in gastric mucosa-associated lymphoid tissue lymphoma cells: clinical and biological significance. Blood Cancer J 2013, 3:e125.

47. Wroblewski LE, Peek RM, Wilson KT: Helicobacter pylori and gastric cancer: factors that modulate disease risk. Clin Microbiol Rev 2010, 23:713-739.

48. Kong Y, Ma LQ, Bai PS, Da R, Sun H, Qi XG, Ma JQ, Zhao RM, Chen NZNK: Helicobacter pylori promotes invasion and metastasis of gastric cancer cells through activation of AP-1 and up-regulation of CACUL1. Int J Biochem Cell Biol 2013, 45:2666-2678.

49. Campos Fl, Koriyama C, Akiba S, Carrasquilla G, Serra M, Carrascal E, Itoh T, Minakami $Y$, Eizuru $Y$ : Environmental factors related to gastric cancer associated with Epstein-Barr virus in Colombia. Asian Pac J Cancer Prev 2006, 7:633-637.

50. Herrera-Goepfert R, Akiba S, Koriyama C, Ding S, Reyes E, Itoh T, Minakami Y, Eizuru Y: Epstein-Barr virus-associated gastric carcinoma: Evidence of age-dependence among a Mexican population. World J Gastroenterol 2005, 11:6096-6103.

51. Hao Z, Koriyama C, Akiba S, Li J, Luo X, Itoh T, Eizuru Y, Zou J: The Epstein-Barr virus-associated gastric carcinoma in Southern and Northern China. Oncol Rep 2002, 9:1293-1298.

52. Gulley ML, Pulitzer DR, Eagan PA, Schneider BG: Epstein-Barr virus infection is an early event in gastric carcinogenesis and is independent of bcl-2 expression and p53 accumulation. Hum Pathol 1996, 27:20-27.

53. Minoura-Etoh J, Gotoh K, Sato R, Ogata M, Kaku N, Fujioka T, Nishizono A: Helicobacter pylori-associated oxidant monochloramine induces reactivation of Epstein-Barr virus (EBV) in gastric epithelial cells latently infected with EBV. J Med Microbiol 2006, 55:905-911.

54. Cárdenas-Mondragón MG, Carreón-Talavera R, Camorlinga-Ponce M, Gomez-Delgado A, Torres J, Fuentes-Pananá EM: Epstein Barr virus and Helicobacter pylori co-infection are positively associated with severe gastritis in pediatric patients. PLoS One 2013, 8:e62850.

doi:10.1186/1471-230X-14-179

Cite this article as: de Souza et al:: Occurrence of Helicobacter pylori and Epstein-Barr virus infection in endoscopic and gastric cancer patients from Northern Brazil. BMC Gastroenterology 2014 14:179.

\section{Submit your next manuscript to BioMed Central and take full advantage of:}

- Convenient online submission

- Thorough peer review

- No space constraints or color figure charges

- Immediate publication on acceptance

- Inclusion in PubMed, CAS, Scopus and Google Scholar

- Research which is freely available for redistribution 